\title{
Chasse-sur-Rhone, Communay
}

Route départementale 150

\section{Serge Martin}

\section{(2) OpenEdition}

\section{Journals}

Édition électronique

URL : http://journals.openedition.org/adlfi/3482

ISSN : 2114-0502

Éditeur

Ministère de la culture

Référence électronique

Serge Martin, "Chasse-sur-Rhone, Communay », ADLFI. Archéologie de la France - Informations [En ligne], Rhône-Alpes, mis en ligne le 01 mars 2009, consulté le 30 avril 2019. URL : http:// journals.openedition.org/adlfi/3482

Ce document a été généré automatiquement le 30 avril 2019.

(C) Ministère de la Culture et de la Communication, CNRS 


\title{
Chasse-sur-Rhone, Communay
}

Route départementale 150

\author{
Serge Martin
}

Identifiant de l'opération archéologique : 10094

Date de l'opération : 2009 (EX)

1 L'aménagement d'un contournement au sud de l'actuel tracé routier de l'A 46, a conduit à réaliser un diagnostic archéologique sur les 5 ha dévolus à la première phase. Dans la portion étudiée, les parcelles sont situées en bordure méridionale du tracé de l'A 46 sud et, parfois, ces terrains constituent la bande de sécurité de ce contournement de l'agglomération lyonnaise. Quarante sondages ont été réalisés mais quatre seulement ont livré les indices d'une occupation.

2 Ces sondages, au lieu-dit "Charvas », ont permis d'identifier un site de l'âge du Fer. Il est situé au pied d'une butte formée par le socle de micaschiste. Deux fosses (F1 et F2) indiquent, par leur mobilier, une occupation de l'âge duFer. La nature de cette installation, localisée en pied de butte, reste encore à définir.

3 La fosse $\mathrm{F} 1$ est de plan circulaire et d'un diamètre de $0,80 \mathrm{~m}$. Elle apparaît à une profondeur de 0,60 m soit à l'altitude NGF de 219,12 m.

4 La fosse F2 appartient au même horizon et est beaucoup plus importante en taille que F1. Elle apparaît plus difficile à cerner car elle présente des parois circulaires sur le coté nord et linéaires au sud qui indiqueraient un ensemble plus complexe. Le comblement supérieur est constitué de fragment de céramiques et d'éléments de combustion (nodules et fragments d'argiles rubéfiés (charbons de bois en surface). La céramique visible en surface a été collectée afin d'apporter une datation. Ce prélèvement a permis de préciser la contemporanéité des deux fosses localisées dans le même sondage et à très peu de distance $(1 \mathrm{~m})$ l'une de l'autre.

5 L'étude de C. Bellon, souligne l'homogénéité du lot céramique. Les vases sont modelés et ont rarement subi des traitements de surface. Les pâtes sont assez grossières, notamment 
les formes hautes et présentent encore des traces de modelage. Les dégraissants sont apparents, nombreux, et le mica est majoritaire, le plus souvent sous la forme de fragments grossiers.

6 L'ensemble est à situer au premier âge du Fer. Certaines formes céramiques sont présentes dès le Hallstatt $C$ comme la jatte carénée à bord concave qui est une forme apparue dès le VIII ${ }^{\mathrm{s}}$., souvent décorée comme au site du Pré de la Cour (Vital, 1993, p. 141, fig. 71, 10, fig. 80,3/5). Pour ce qui concerne les écuelles, on remarquera ici que les formes sont assez profondes, leurs panses, convexe, ne portent aucun décor, l'inflexion des bords n'est pas très marquée, les lèvres sont rarement aplaties, souvent arrondies. Leur bonne représentation - bien que le lot soit peu conséquent - est là aussi un bon marqueur pour le I $\mathrm{I}^{\mathrm{er}}$ âge du Fer, la fréquence de ces formes ne cessant de croître durant cette période. Les pots tonneaux, ici inornés, sont le plus souvent décorés (incisions, petites impressions, ou porteurs de cordons); apparus au Bronze final $3 \mathrm{~b}$, ils sont caractéristiques du $\mathrm{e}^{\mathrm{er}}$ âge du Fer, jusque dans des contextes Hallstatt D3 (Bellon, 2009, fig. 11 ; Vital, 1993, fig. 72, n 1 , fig. 78, $n^{\circ} 3$ ).

7 On notera des absences à valeur chronologique, telles par exemple celles des formes présentes depuis le Bronze final $3 \mathrm{~b}$ ou typiques du tout début du Ier âge du Fer comme en livrent les sites régionaux du Pré de la Cour, Barlières (Ain), Saint-Priest Les Perches (Rhône), ou plus au sud, Valence (Drôme) : jatte à panse arrondie et lèvre biseautée, ou petites jattes à faibles cannelures ou surbaissées à carène marquée, coupes à flanc redressé et lèvres biseautées, pots à décor impressionné sur ressaut... (voir Vital, 1993, p. 150 ; Hénon et al.,2003, p.16-18 ; Ramponi, 2004, vol. 2, fig. 3-58). Peut-être faut-il exclure une datation dans le courant $\mathrm{du} \mathrm{VIII}^{\mathrm{e}} \mathrm{s}$ ? Pour ce qui concerne la fin de l'âge duFer, c'est ici l'absence d'importations méditerranéennes (amphores massaliètes, vaisselier du sud de la Gaule), ou de céramiques réalisées au tour qui semble exclure le Hallstatt D3. Toutefois, la modestie du lot incite à rester prudent sur la valeur d'un raisonnement par absence.

On rappellera que le site de La Raze de la Dame sur la même commune de Communay, a livré des vestiges de structures d'habitat protohistoriques de la fin de l'âge du Bronze, du Hallstatt $D 3$ et de La Tène $C$ qui montrent une certaine densité des occupations protohistoriques sur ce secteur (Sandoz, Thiériot, Vital, 1993).

\section{INDEX}

Thèmes : céramique, fosse

Index géographique : Rhône-Alpes, Isère, Chasse-sur-Rhône

Index chronologique : Âge du Fer

operation expertise (EX) 
AUTEUR

SERGE MARTIN 